\title{
Postoperative empyema following lung cancer surgery
}

\author{
Noriyuki Matsutani ${ }^{1}$, Katsuo Yoshiya ${ }^{2}$, Masayuki Chida ${ }^{3}$, Hirozo Sakaguchi ${ }^{4}$, Takuma \\ Kikkawa5, Hiroki Fukuda6, Nobumasa Takahashi7, Noriyoshi Sawabata', Hirotoshi \\ Horio ${ }^{9}$, Nobuhiko Seki ${ }^{1}$ and Masafumi Kawamura ${ }^{1}$ \\ ${ }^{1}$ Department of Surgery, Teikyo University School of Medicine, Tokyo, Japan \\ ${ }^{2}$ Department of Thoracic Surgery, Niigata Cancer Center Hospital, Niigata, Japan \\ ${ }^{3}$ Department of General Thoracic Surgery, Dokkyo Medical University, Tochigi, Japan \\ ${ }^{4}$ Department of General Thoracic Surgery, Saitama International Medical Center, Saitama Medical University, Saitama, Japan \\ ${ }^{5}$ Department of Surgery I, Tokyo Women's Medical University, Tokyo, Japan \\ ${ }^{6}$ Department of General Thoracic Surgery, Saitama Medical Center, Saitama Medical University, Saitama, Japan \\ ${ }^{7}$ Department of Thoracic Surgery, Saitama Cardiovascular and Respiratory Center, Saitama, Japan \\ ${ }^{8}$ Department of Thoracic and Cardiovascular Surgery, Nara Medical University, Nara, Japan \\ ${ }^{9}$ Department of General Thoracic Surgery, Tokyo Metropolitan Cancer and Infectious Diseases Center Komagome Hospital, \\ Tokyo, Japan
}

Correspondence to: Noriyuki Matsutani, email: matsutani1970@yahoo.co.jp

Keywords: empyema; lung cancer; postoperative infection; surgery; mortality

Abbreviations: VATS: video-assisted thoracic surgery

Received: February 27, $2018 \quad$ Accepted: June 04, $2018 \quad$ Published: July 03, 2018

Copyright: Matsutani et al. This is an open-access article distributed under the terms of the Creative Commons Attribution License 3.0 (CC BY 3.0), which permits unrestricted use, distribution, and reproduction in any medium, provided the original author and source are credited.

\section{ABSTRACT}

Postoperative empyema following lung cancer surgery is a serious complication. Occurrence rate of postoperative empyema following lung cancer surgery, patient background, surgical procedures, date of empyema onset, treatment, and prognosis of 4772 patients who underwent lung cancer surgery between 2008 and 2012 were investigated.

Postoperative empyema following lung cancer surgery was found in $\mathbf{4 3}$ patients $(0.9 \%)$. The occurrence rate of postoperative empyema was significantly higher in patients with the following factors: male gender, extended surgery such as pneumonectomy, bi-lobectomy and thoracotomy, squamous cell carcinoma, and an advanced pathologic stage of II and above. Chest drainage, video-assisted thoracic surgery debridement, fenestration, and thoracoplasy were performed, where 29 patients were cured $(67.5 \%)$ and 5 patients $(11.6 \%)$ died from thoracic empyemarelated complications. Nine patients were not cured and died due to cancer or other diseases during treatment. When comparing cured and non-cured patients, it is indicated that squamous cell carcinoma, administration of steroids, history of interstitial pneumonia, presence of bronchial stump fistula, exacerbation of interstitial pneumonia and presence of non-fermenting Gram-negative bacilli led to a significantly low prognosis. The five-year overall survival rate was $34.9 \%$.

\section{INTRODUCTION}

Empyema is the main cause of death and causes serious complications within 30 days following lung cancer surgery [1]. Moreover, postoperative empyema prolongs hospitalization and postpones subsequent treatment. It has been reported that the occurrence rate for development of postoperative empyema before 2000 was between 3.7 and $13.6 \%$ [2-8]. In recent years, due to progress in perioperative management as well as the use of perioperative prophylactic antibiotics, the occurrence rate of empyema is approximately $1 \%$ [9-11]. On the other 
hand, the risk in developing postoperative complications is increasing due to increased comorbidity caused by perioperative chemotherapy and advanced patient age [6]. Reports on factors inducing postoperative empyema and treatments and prognosis for postoperative empyema have been scarcely available. In this retrospective multicenter study, the risk factors for developing postoperative empyema following lung cancer surgery and its prognosis were conducted.

\section{RESULTS}

Of 4772 patients, 3035 patients were male, and 1737 patients were female. There were 3471 patients under the age of 75 years and 1301 patients over the age of 75 years. The number of patients who underwent lobectomy was the largest, being 3326, followed by segmentectomy, wedge resection, bi-lobectomy, and pneumonectomy, where the numbers were $651,585,111$, and 91, respectively. Thoracotomy and video-assisted thoracic surgery (VATS) were performed on 3405 and 1367 patients, respectively. Sleeve resection and induction therapy were performed on 118 and 114 patients, respectively. Three thousand two hundred ninety patients were in Stage I and 652 patients in Stage II, while there were 827 patients in Stages III and IV. Histological analysis indicated that 3322 patients had adenocarcinoma and 1046 patients had squamous cell carcinoma (Table 1).

Postoperative empyema was found in 43 patients (43/4772, 0.90\%), where 37 patients were male and 6 patients were female, showing a significant gender difference $(p=0.002)$, although no difference was found by age. Surgical procedure which caused the highest postoperative empyema occurrence rate was pneumonectomy followed by bi-lobectomy, which were significantly higher than that of lobectomy, segmentectomy, and wedge resection $(p<0.001)$. Moreover, the number of patients who underwent thoracotomy showed a higher occurrence rate of postoperative empyema compared with those who underwent VATS $(p=0.005)$. There was no significant difference in the occurrence rate of postoperative empyema between patients who underwent sleeve resection, or patients who underwent induction therapy. Histological analysis indicated that a higher frequency of postoperative empyema was found in patients with squamous cell carcinomacompared with those with non-squamous cell carcinoma $(p=0.009)$. Patients in Stage I developed fewer postoperative empyema compared with those in Stages II, III, or IV ( $p=0.005)$ (Table 1).

Among the 43 patients with postoperative empyema, the causes of empyema were bronchial stump fistula in 14 patients, retrograde infection due to a chest tube in 12 patients, bronchopleural fistula in 11 patients, exacerbation of interstitial pneumonia in 4 patients, intraoperative contamination in 3 patients, surgical site infection in 3 patients, and pneumonia in 3 patients.
The date when postoperative empyema was first observed was between the 4th and 425th day (average being 43.9th day) while 29 patients developed postoperative empyema early within 30 days and 14 patients developed late after 30 days. Pleural effusion samples were collected from 43 patients to examine the presence of bacteria by culturing. Of 43 samples, 37 samples contained a total of 46 types of bacteria, where MRSA was found in 10 samples, MSSA was in 9 samples, Pseudomonas was in 6 samples, Enterococcus was in 4 samples, and other types of bacteria were found in 16 samples (Table 2).

Of 43 postoperative empyema patients, 39 patients underwent chest drainage as an initial treatment, and while 13 of these were cured, 2 died due to empyema-related diseases and 1 died due to other disease during treatment. VATS debridement was added to the initial chest drainage for 9 patients and fenestration and thoracoplasy were added to 14 patients. Four patients underwent fenestration and thoracoplasy as the initial treatment, and while 1 of them was cured, 1 died from empyema-related causes and 2 were not cured. Of 9 patients who received VATS debridement as a secondary treatment, 8 patients were cured while 1 patient was not cured. Moreover, of 14 patients who received fenestration and thoracoplasy as a secondary treatment, 7 patients were cured while 2 patients died from empyemarelated causes and 5 patients were not cured. Thus, 5 patients with postoperative empyema died from empyema-related causes resulting in a mortality rate of $11.6 \%$ (Figure 1 ).

Twenty-nine patients $(67.5 \%)$ were cured while of the 14 non-cured patients, there were 5 patients who died from empyema-related causes. Six patients died from cancer during empyema treatment, 2 patients died from other diseases, and 1 patient committed suicide.

When comparing cured and non-cured patients, it is indicated that gender, age, type of surgery, and pathologic stage did not impact prognosis of the disease; however, squamous cell carcinoma, administration of steroid, history of interstitial pneumonia, presence of bronchial stump fistula, exacerbation of interstitial pneumonia and presence of non-fermenting Gram-negative bacilli led to a significantly low prognosis (Table 2).

Risk factors selected by univariate analysis were subjected to multivariate analysis; however, no independent risk factors were found (Table 3).

The 3-year and 5-year cancer free survival rates were $41.4 \%$ and $34.4 \%$, respectively (Figure 2A). Regarding survival rates, the 3-year and 5-year overall survival rates were $47.9 \%$ and $34.9 \%$, respectively, with an average observation period and observation median being 46.8 months and 36 months, respectively (Figure 2B). The 3-year overall survival rates by pathologic stage were $57.1 \%$ for stage I, $54.5 \%$ for stage II, and $20.5 \%$ for stage III and IV, while the 5-year overall survival rates were $41.9 \%$ for stage I, $54.5 \%$ for stage II, and $0 \%$ for stage III and IV. The difference in overall survival was statistically significant between stage I and stage III 
Table 1: Patient characteristics

\begin{tabular}{|c|c|c|c|c|}
\hline Variable & $\begin{array}{l}\text { Lung cancer surgery } \\
\qquad(n=4772)\end{array}$ & $\begin{array}{l}\text { Empyema } \\
(n=43)\end{array}$ & $\%$ & $p$-value \\
\hline Total number & 4772 & 43 & 0.90 & \\
\hline \multicolumn{5}{|l|}{ Sex } \\
\hline Male & 3035 & 37 & 1.22 & \multirow[t]{2}{*}{0.002} \\
\hline Female & 1737 & 6 & 0.35 & \\
\hline \multicolumn{5}{|l|}{ Age } \\
\hline$<75$ & 3471 & 29 & 0.84 & \multirow[t]{2}{*}{0.39} \\
\hline$\geq 75$ & 1301 & 14 & 1.08 & \\
\hline \multicolumn{5}{|l|}{ Procedure } \\
\hline Pneumonectomy & 91 & 8 & 8.79 & \multirow[t]{5}{*}{$<0.0001$} \\
\hline Bi-lobectomy & 111 & 3 & 2.70 & \\
\hline Lobectomy & 3326 & 26 & 0.78 & \\
\hline Segmentectomy & 651 & 5 & 0.77 & \\
\hline Wedge resection & 585 & 1 & 0.17 & \\
\hline \multicolumn{5}{|l|}{ Method } \\
\hline Thoracotomy & 3405 & 39 & 1.15 & \multirow[t]{2}{*}{0.005} \\
\hline Video-assisted thoracic surgery & 1367 & 4 & 0.29 & \\
\hline Sleeve resection & 118 & 2 & 1.69 & 0.355 \\
\hline Induction therapy & 114 & 2 & 1.75 & 0.329 \\
\hline \multicolumn{5}{|l|}{ Pathologic stage } \\
\hline I & 3290 & 21 & 0.64 & \multirow[t]{3}{*}{0.005} \\
\hline II & 652 & 11 & 1.69 & \\
\hline III, IV & 827 & 11 & 1.33 & \\
\hline \multicolumn{5}{|l|}{ Histology } \\
\hline Squamous cell ca. & 1046 & 16 & 1.53 & \multirow[t]{8}{*}{0.009} \\
\hline Non-squamous cell ca. & 3726 & 27 & 0.72 & \\
\hline adenocarcinoma & 3322 & 21 & 0.63 & \\
\hline large cell ca. & 110 & 1 & 0.91 & \\
\hline small cell ca. & 76 & 1 & 1.32 & \\
\hline adenosquamous ca. & 67 & 1 & 1.49 & \\
\hline pleomorphic ca. & 62 & 2 & 3.23 & \\
\hline others & 97 & 1 & 1.03 & \\
\hline
\end{tabular}

and IV $(p=0.032)$, whereas no significant differences were shown between stage I and stage II $(p=1.000)$, and between stage II and stage III and IV $(p=0.081)$ (Figure 2C).

\section{DISCUSSION}

Reports regarding postoperative empyema following lung cancer surgery had been derived from a single institution where the lung cancer surgery numbers were between 199 and 1855 (Table 4) [2-8, 10, 11]. In this manuscript, 4773 patients who underwent lung cancer surgery at multiple centers were studied. Although Nagasaki reported that the occurrence rate of postoperative empyema following lung cancer surgery was $0.9 \%$ before 2000 , it was commonly understood that the actual rate was $3.7-13.6 \%$, while the rate after 2000 was reported to be approximately $1 \%$ (Table 4 ) $[2-8,10,11]$. The reasons for the improvement in the occurrence rate of empyema were thought to be derived from improvements in perioperative management [10].

Pneumonectomy can be a risk factor which can cause postoperative empyema [3, 5, 8]. Excluding the report published by Nagasaki where the rate of 


\begin{tabular}{|c|c|c|c|c|}
\hline Variable & $n$ & $\begin{array}{c}\begin{array}{c}\text { Cure } \\
(n=29)\end{array} \\
\end{array}$ & $\begin{array}{c}\begin{array}{c}\text { Non-cure } \\
(n=14)\end{array} \\
\end{array}$ & $p$-value \\
\hline \multicolumn{5}{|l|}{ Sex } \\
\hline Male & 37 & 24 & 13 & \multirow[t]{2}{*}{0.371} \\
\hline Female & 6 & 5 & 1 & \\
\hline \multicolumn{5}{|l|}{ Age } \\
\hline$<75$ & 29 & 20 & 9 & \multirow[t]{2}{*}{0.759} \\
\hline$\geq 75$ & 14 & 9 & 5 & \\
\hline \multicolumn{5}{|l|}{ Method } \\
\hline Thoracotomy & 39 & 26 & 13 & \multirow[t]{2}{*}{0.735} \\
\hline Video-assisted thoracic surgery & 4 & 3 & 1 & \\
\hline \multicolumn{5}{|l|}{ Pathologic stage } \\
\hline I & 21 & 13 & 8 & \multirow[t]{2}{*}{0.449} \\
\hline II, III, IV & 22 & 16 & 6 & \\
\hline \multicolumn{5}{|l|}{ Histology } \\
\hline Squamous cell ca. & 16 & 7 & 9 & \multirow[t]{2}{*}{0.011} \\
\hline Non-squamous cell ca. & 27 & 22 & 5 & \\
\hline \multicolumn{5}{|l|}{ Procedure } \\
\hline Pneumonectomy, Bi-lobectomy & 11 & 5 & 6 & \multirow[t]{2}{*}{0.071} \\
\hline Others & 32 & 24 & 8 & \\
\hline \multicolumn{5}{|l|}{ Pre-operative complications } \\
\hline Hypertension & 14 & 8 & 6 & 0.371 \\
\hline Chronic obstructive pulmonary disease & 6 & 4 & 2 & 0.965 \\
\hline Administration of steroid & 5 & 1 & 4 & 0.016 \\
\hline Other organs cancer & 4 & 3 & 1 & 0.735 \\
\hline Diabetes mellitus & 4 & 2 & 2 & 0.434 \\
\hline Ischemic heart disease & 3 & 1 & 2 & 0.191 \\
\hline Cerebrovascular disease & 3 & 2 & 1 & 0.976 \\
\hline Interstitial pneumonia & 2 & 0 & 2 & 0.037 \\
\hline \multicolumn{5}{|l|}{ Date of onset } \\
\hline$<30$ days & 29 & 20 & 9 & \multirow[t]{2}{*}{0.759} \\
\hline$\geq 30$ days & 14 & 9 & 5 & \\
\hline \multicolumn{5}{|l|}{ Cause of empyema } \\
\hline Bronchial stump fistula & 14 & 6 & 8 & 0.017 \\
\hline Retrograde infection by chest tube & 12 & 12 & 0 & 0.005 \\
\hline Bronchopleural fistula & 11 & 7 & 4 & 0.755 \\
\hline Exacerbation of interstitial pneumonia & 4 & 0 & 4 & 0.003 \\
\hline Intraoperative contamination & 3 & 2 & 1 & 0.976 \\
\hline Surgical site infection & 3 & 3 & 0 & 0.212 \\
\hline Pneumonia & 3 & 3 & 0 & 0.212 \\
\hline \multicolumn{5}{|l|}{ Microbiology } \\
\hline MRSA & 10 & 5 & 5 & 0.179 \\
\hline MSSA & 9 & 8 & 1 & 0.123 \\
\hline Pseudomonas aeruginosa & 6 & 4 & 2 & 0.965 \\
\hline
\end{tabular}


Enterobacteriaceae

Enterococci

Aspergillus

Nontuberculous mycobacteria

Haemophilus influenzae

Anaerobe

Gram-positive coccus

Non-fermenting Gram-negative bacilli

Corynebacterium spp

Abbreviations: MRSA: Methicillin-resistant Staphylococcus aureus; MSSA: Methicillin-susceptible Staphylococcus aureus.

pneumonectomy was $8 \%[4]$, the rate of pneumonectomy as a surgical technique used before 2000 was extremely high, being $17.2-45.3 \%$ [5-8]. In recent years, the incidence of pneumonectomy has decreased to $1.9-4.7 \%$; thus, the occurrence rate of postoperative empyema cases is decreasing as pneumonectomy is performed less frequently $[10,11]$. Other risk factors such as gender being male $[6,10]$, being elderly $[6,10]$, induction therapy [6], and diabetes mellitus [8], are reported as risk factors which can cause postoperative empyema. It has been reported that decreased immunological response of patients due to advanced disease stage and extended surgery can impact the development of postoperative empyema [5].

In this study, the occurrence rate of postoperative empyema was significantly higher in patients with factors including male gender, extended surgical procedures such as pneumonectomy and bi-lobectomy, thoracotomy, squamous cell carcinoma, and an advanced pathologic stage of II and above. Patients at an advanced pathologic stage with squamous cell carcinoma require pneumonectomy; thus, it is thought that these conditions may result in the development of postoperative empyema following lung

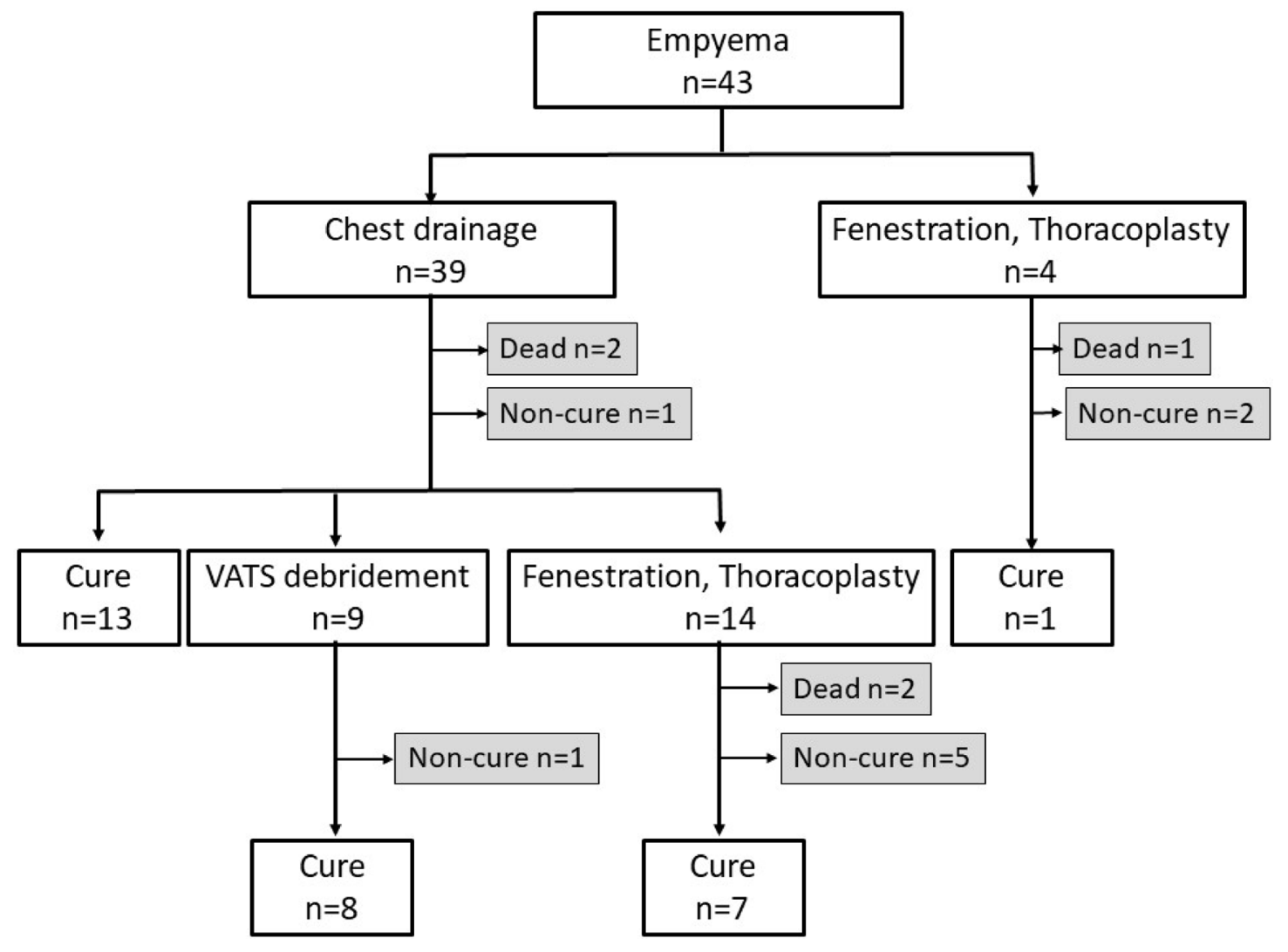

Figure 1: Treatment flowchart of postoperative empyema. VATS: video-assisted thoracic surgery. 
Table 3: Prognostic factors: multivariate analysis of Cox proportional hazards model

\begin{tabular}{lccc}
\hline Variable & risk ratio & $\mathbf{9 5 \%}$ CI & $\boldsymbol{p}$-value \\
\hline Cause of empyema & & & \\
Exacerbation of interstitial pneumonia & 0 & 0.00 & 0.999 \\
Bronchial stump fistula & 0.371 & $0.064-2.165$ & 0.558 \\
Pre-operative complication & & & \\
Administration of steroid & 0.188 & $0.008-4.311$ & 0.296 \\
Interstitial pneumonia & 1.844 & 0.00 & 1 \\
Histology & & & 0.223 \\
Squamous cell ca. & 0.325 & $0.053-1.982$ & \\
Microbiology & & & 0.999 \\
Non-fermenting Gram(-) bacilli & 0 & 0.00 &
\end{tabular}

cancer surgery. In recent years, it is considered that the increased use of minimally invasive surgery such as VATS, instead of thoracotomy, may help to reduce the number of postoperative empyema occurrences $[12,13]$.

Reports on factors inducing postoperative empyema and treatments and prognosis for postoperative

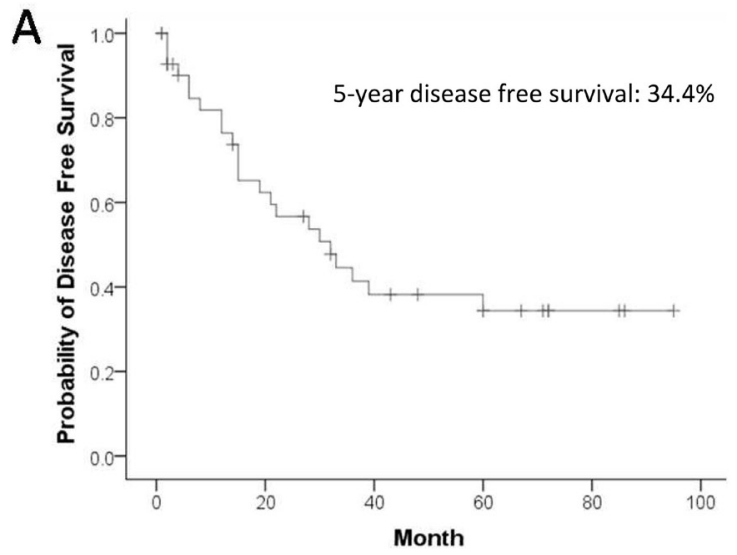

empyema have been scarcely available; thus, this study is the first to report on these questions. According to this study, it was discovered that empyema in 58.2\% of patients was due to fistulas such as bronchial stump fistula and bronchopleural fistula. Among these fistulas, the prognosis for bronchial stump fistula is significantly

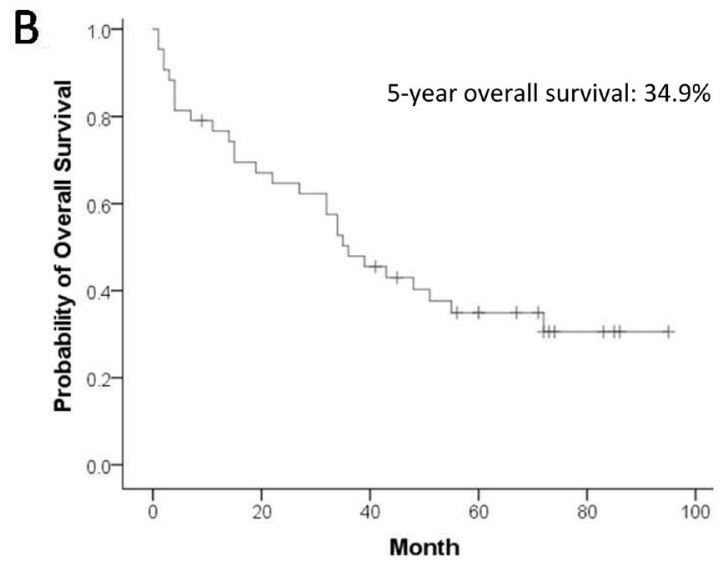

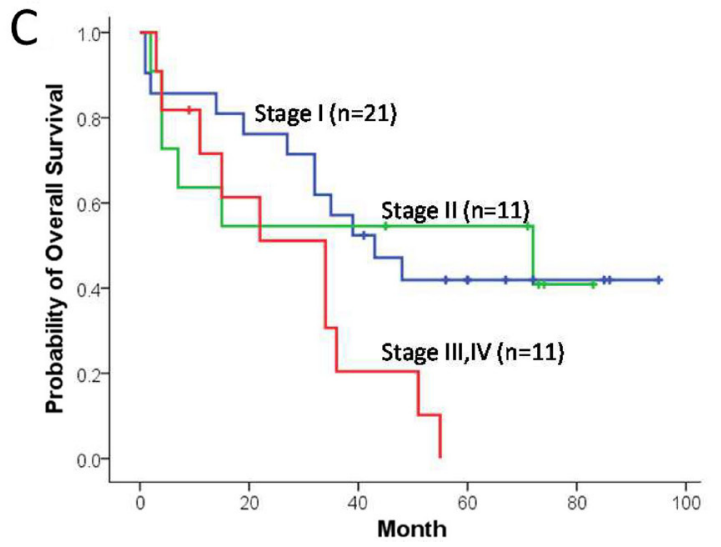

Figure 2: Cancer free survival curve (A), overall survival curve (B) and pathologic stage-specific survival curves, stage I $(n=21$, blue), stage II ( $n=11$, green), and stage III and IV $(n=11$, red) (stage I vs. II; $p=1.000$, stage I vs. III and IV; $p=0.032$, stage II vs. III and IV; $p=0.081)(\mathbf{C})$. 
Table 4: Literature on postoperative empyema in lung cancer surgery

\begin{tabular}{lccccccc}
\hline Author (year) & Period & Institution & Surgery & Empyema & Incidence & Mortarity & 5-year survival \\
\hline Ruckdeschel (1972) & $1952-1966$ & single & 489 & 18 & $3.7 \%$ & $\mathrm{n} / \mathrm{a}$ & $50.0 \%$ \\
Brohee (1977) & $1961-1972$ & single & 349 & 45 & $12.9 \%$ & $\mathrm{n} / \mathrm{a}$ & $20.0 \%$ \\
Pastorino (1982) & $1974-1977$ & single & 199 & 27 & $13.6 \%$ & $14.8 \%$ & $28.0 \%$ \\
Nagasaki (1982) & $1973-1980$ & single & 961 & 9 & $0.9 \%$ & $22.2 \%$ & $\mathrm{n} / \mathrm{a}$ \\
Deslauriers (1994) & $1988-1989$ & multiple & 783 & 39 & $5.0 \%$ & $\mathrm{n} / \mathrm{a}$ & $\mathrm{n} / \mathrm{a}$ \\
Giorgio (1996) & $1960-1984$ & single & 460 & 38 & $8.3 \%$ & $\mathrm{n} / \mathrm{a}$ & $36.8 \%$ \\
Duque (1997) & $1993-1994$ & multiple & 605 & 27 & $4.5 \%$ & $\mathrm{n} / \mathrm{a}$ & $\mathrm{n} / \mathrm{a}$ \\
Shiono (2007) & $1992-2003$ & single & 1855 & 18 & $1.0 \%$ & $\mathrm{n} / \mathrm{a}$ & $\mathrm{n} / \mathrm{a}$ \\
Yamauchi (2013) & $2002-2011$ & single & 1673 & 27 & $1.6 \%$ & $\mathrm{n} / \mathrm{a}$ & $\mathrm{n} / \mathrm{a}$ \\
This study & $2008-2012$ & multiple & 4772 & 43 & $0.9 \%$ & $11.6 \%$ & $34.9 \%$ \\
\hline
\end{tabular}

poor and the fistula is difficult to cure. The next highest factor, $27.9 \%$ of empyema patients, which induces empyema is retrograde infection due to a chest tube; however, all of them were cured. On the other hand, none of the empyema patients with interstitial pneumonia were cured. Thirty-nine $(90.7 \%)$ of the empyema patients underwent chest drainage as an initial treatment of empyema while 4 patients $(9.3 \%)$ underwent fenestration from the beginning. While thirteen empyema patients $(30.2 \%)$ were cured by chest drainage alone, another 23 chest drainage patients required additional treatment by VATS debridement or fenestration.

Empyema is a fatal condition in itself where the death rate due to empyema is $10-16 \%$ [14-16]. The death rate of patients with postoperative empyema following lung cancer surgery was $14.8-22.2 \%$ according to reports published in $1982[4,5]$. In this study, the death rate of patients with postoperative empyema was $11.6 \%$, the rate being approximately the same as empyema patients who did not undergo surgery.

The death rate for patients following lung cancer surgery in Japan was $1.6 \%$ before 2002, where $33 \%$ of such deaths were caused by bronchial stump fistula and empyema $(19 / 3270 ; 0.581 \%)$ [1]. The death rate of patients following lung cancer surgery is $0.7-0.8 \%$ since 2010 , where $6.2-9.1 \%$ of such deaths are caused by bronchial stump fistula and empyema $(41 / 32,801 ; 0.125 \%$ [12], 20/38,085; $0.053 \%$ [13], this study 5 of $4772 ; 0.105 \%$ ). Thus, the death rate following lung cancer surgery has decreased.

The risk factors which impact prognosis of empyema, including a cancer type being squamous cell carcinoma, administration of steroids, history of interstitial pneumonia, presence of bronchial stump fistula, exacerbation of interstitial pneumonia, and presence of non-fermenting Gram-negative bacilli possibly turning to drug resistance, were identified by univariate analysis. No independent risk factors were identified by multivariate analysis. However, the reasons may be due to the small patient number and each factor playing a confounding factor.
Postoperative empyema was thought to increase immune response, which improves the prognosis of lung cancer [2, 17-20]. This hypothesis came from an initial discovery by Dr. Graham where he performed the first successful pneumonectomy on a patient with lung cancer who survived longer than 30 years following postoperative empyema [21]. On the other hand, there are reports that empyema does not improve the prognosis of patients with lung cancer [3,5]. Neither case is convincing since patient numbers were small and controls were not adequate. In this study, the 5-year overall survival rate for all postoperative empyema was $34.9 \%$, where by disease stage was $41.9 \%$ at stage I, $54.5 \%$ at stage II, and $0 \%$ at stages III and IV. In a prognosis study conducted in Japan, the 5-year survival rate of 11,663 patients by disease stage following lung cancer surgery was $86.8 \%$ at stage IA, $73.9 \%$ at stage IB, $61.6 \%$ at stage IIA, $49.8 \%$ at stage IIB, $40.9 \%$ at stage IIIA, $27.8 \%$ at stage IIIB, and $27.9 \%$ at stage IV [22]. The number of patients with postoperative empyema was small and therefore it is not adequate to compare data from the 2 different studies; however, it may not be true that postoperative empyema improves prognosis of patients who underwent lung cancer surgery.

Postoperative empyema following lung cancer surgery is a serious complication. However, no reports on treatments of empyema and prognosis of patients with empyema have been published. This study is retrospective. However, the data were collected from 4772 patients who underwent lung cancer surgery and the actual cause, treatment, and prognosis of empyema were reported.

There were some limitations of this study. Detailed analysis was possible for only 43 patients with postoperative empyema, however, detailed information regarding past history, complications, operative time, blood loss during surgery, coverage of the bronchial stump and prognosis of other patients who underwent lung cancer surgery was difficult to obtain. Because of the multi-institutional study, the surgical procedures, and the perioperative management were different among 
institutions. Although the occurrence rate, inducing factors and prognosis for postoperative empyema were indicated, to assess and plan for patients with the risk preoperatively cannot be devised from this study. Based on this study, future prospective studies of postoperative empyema are anticipated.

Lung cancer surgery is becoming minimally invasive, reducing the occurrence rate of postoperative empyema following lung cancer surgery to $0.9 \%$. This report determined that male gender, extended surgery, open thoracotomy, squamous cell carcinoma, and advanced stage were risk factors inducing postoperative empyema following lung cancer surgery. The cure rate was $67.5 \%$, and the mortality rate was $11.6 \%$.

\section{MATERIALS AND METHODS}

This study was approved by the Institutional Ethics Review Board (Teikyo University Review Board 12-152) and other institutions, and the need for informed consent from patients was waived provided that patient data remained anonymous.

\section{Patients}

This study was conducted on 4772 patients who underwent thoracic surgery to treat primary lung cancer between January, 2008 and December, 2012 at 9 institutions in Japan. The surgical indications and procedures for lung cancer were determined by each institution. All the participating institutions were certified by The Japanese Association for Chest Surgery, and respiratory surgery specialists performed treatment according to Lung Cancer Clinical Practice Guidelines by The Japan Lung Cancer Society, where patients with performance status 0 and 1 were subjects undergoing surgery. Perioperative management at each institution was approximately the same. An antibiotic, Cefazolin at 7 institutions and Piperacillin at 2 institutions, was administered prophylactically to patients beginning immediately before surgery. Administration of antibiotics was ended on the day after surgery at 2 institutions, on the next day after surgery at 3 institutions, on the 2 nd day after surgery at 2 institutions, and on the 3rd day after surgery at 2 institutions. Antibiotics and duration of antibiotics used were modified depending on the symptoms of infection. A chest tube (size: 19-28Fr) was installed in the pleural space at the time of chest closure. The chest tube was removed when air leakage, hemothorax, and chylothorax were not observed and when the amount of pleural effusion was less than $300 \mathrm{~mL}$ per day. No institution conducted bacterial culture from the chest tube tip.

\section{Definitions}

Purulent effusion collection in the postoperative thoracic cavity with over Grade IIIa of Clavien-Dindo classification is defined as empyema. The bacterial culture results of purulent effusion were not accounted for. Cancers were pathologically classified according to the eighth edition of the TNM classification for lung cancer according to the international association for the study of lung cancer [23]. Video-assisted thoracic surgery was defined as surgery with a thoracoscopic field of view, and a chest metallic retractor was not used, in this study.

\section{Data collection}

The following data were collected from patients with postoperative empyema after lung cancer surgery: gender, age, pre-operative complications, treatment for the lung cancer, date of surgery, type of surgery, type of histology, pathologic stage (I, or II/III/IV), date of empyema confirmed, cause of empyema, bacterial test of pleural effusion, treatment for the empyema, date of lung cancer recurrence, and disease status during followup. Patients were selected by each institution from those whose causes of empyema were intraoperative contamination, infection from surgical site, retrograde infection due to a chest tube, bronchial stump fistula, bronchopleural fistula, pneumonia, interstitial pneumonia, unknown, and others. Intraoperative contamination is the contamination by exposure of pulmonary contents and sputum during operation, and retrograde infection due to a chest tube is the contamination of chest drain penetration site or back flow of contents of drainage bag. The doctor in charge raised the causes which seemed appropriate. Data regarding gender, age, type of surgery, type of histology, and pathologic stage were collected from the 4772 patients included in the study.

\section{Statistical analysis}

Chi-square and Student's $t$-test were used to compare the percentages and mean values. Overall survival and disease-free survival were analyzed using the Kaplan-Meier method. Univariate and multivariate Cox proportional hazards regression analyses were used to evaluate potential prognostic factors. Data were analyzed using version 24 of the IBM SPSS software (IBM Corporation, Somers, NY, USA). A $p$-value $<0.05$ was considered statistically significant.

\section{Author contributions}

Conception and design: N Matsutani; Administrative support: N Matsutani, N Seki, M Kawamura; Provision of study, collection and assembly of data: All authors; Data 
analysis and interpretation: N Matsutani, M Kawamura; All authors have reviewed and agreed to this manuscript.

\section{CONFLICTS OF INTEREST}

All authors have no conflicts of interest to declare.

\section{FUNDING}

None.

\section{REFERENCES}

1. Watanabe S, Asamura H, Suzuki K, Tsuchiya R. Recent results of postoperative mortality for surgical resections in lung cancer. Ann Thorac Surg. 2004; 78:999-1002. https:// doi.org/10.1016/j.athoracsur.2004.04.007.

2. Ruckdeschel JC, Codish SD, Stranahan A, McKneally MF. Postoperative empyema improves survival in lung cancer. Documentation and analysis of a natural experiment. N Engl J Med. 1972; 287:1013-7. https://doi.org/10.1056/ NEJM197211162872004.

3. Brohee D, Vanderhoeft P, Smets P. Lung cancer and postoperative empyema. Eur J Cancer. 1977; 13:1429-36. https://doi.org/10.1016/0014-2964(77)90157-8.

4. Nagasaki F, Flehinger BJ, Martini N. Complications of surgery in the treatment of carcinoma of the lung. Chest. 1982; 82:25-9. https://doi.org/10.1378/chest.82.1.25.

5. Pastorino U, Valente M, Piva L, Ravasi G. Empyema following lung cancer resection: risk factors and prognostic value on survival. Ann Thorac Surg. 1982; 33:320-3. https://doi.org/10.1016/S0003-4975(10)63221-3.

6. Deslauriers J, Ginsberg RJ, Piantadosi S, Fournier B. Prospective assessment of 30-day operative morbidity for surgical resections in lung cancer. Chest. 1994; 106:329S30S. https://doi.org/10.1378/chest.106.6_Supplement.329S.

7. Di Giorgio A, Sammartino P, Arnone P, Canavese A, Almansour M. Prognostic significance of postoperative empyema in lung cancer. Int Surg. 1996; 81:407-11.

8. Duque JL, Ramos G, Castrodeza J, Cerezal J, Castanedo M, Yuste MG, Heras F, and Grupo Cooperativo de Carcinoma Broncogénico de la Sociedad Española de Neumología y Cirugía Torácica. Early complications in surgical treatment of lung cancer: a prospective, multicenter study. Ann Thorac Surg. 1997; 63:944-50.

9. Olak J, Jeyasingham K, Forrester-Wood C, Hutter J, al-Zeerah M, Brown E. Randomized trial of one-dose versus six-dose cefazolin prophylaxis in elective general thoracic surgery. Ann Thorac Surg. 1991; 51:956-8. https:// doi.org/10.1016/0003-4975(91)91014-M.

10. Shiono S, Yoshida J, Nishimura M, Hagiwara M, Hishida T, Nitadori J, Nagai K. Risk factors of postoperative respiratory infections in lung cancer surgery. J Thorac Oncol. 2007; 2:34-8. https://doi.org/10.1097/JTO.0b013e31802bafb6.
11. Yamauchi Y, Isaka M, Maniwa T, Takahashi S, Kurai H, Ohde Y. Chest tube tip culture as a predictor of postoperative infection in lung cancer operations. Ann Thorac Surg. 2013; 96:1796-802. https://doi.org/10.1016/j.athoracsur.2013.06.043.

12. Kuwano H, Amano J, Yokomise H. Thoracic and cardiovascular surgery in Japan during 2010 : annual report by The Japanese Association for Thoracic Surgery. Gen Thorac Cardiovasc Surg. 2012; 60:680-708. https://doi. org/10.1007/s11748-012-0119-y.

13. Masuda M, Okumura M, Doki Y, Endo S, Hirata Y, Kobayashi J, Kuwano H, Motomura N, Nishida H, Saiki Y, Saito A, Shimizu H, Tanaka F, et al, and Committee for Scientific Affairs, The Japanese Association for Thoracic Surgery. Thoracic and cardiovascular surgery in Japan during 2014 : Annual report by The Japanese Association for Thoracic Surgery. Gen Thorac Cardiovasc Surg. 2016; 64:665-97.

14. Farjah F, Symons RG, Krishnadasan B, Wood DE, Flum DR. Management of pleural space infections: a population-based analysis. J Thorac Cardiovasc Surg. 2007; 133:346-51. https://doi.org/10.1016/j.jtcvs.2006.09.038.

15. Maskell NA, Davies CW, Nunn AJ, Hedley EL, Gleeson FV, Miller R, Gabe R, Rees GL, Peto TE, Woodhead MA, Lane DJ, Darbyshire JH, Davies RJ, and First Multicenter Intrapleural Sepsis Trial (MIST1) Group. U.K. Controlled trial of intrapleural streptokinase for pleural infection. $\mathrm{N}$ Engl J Med. 2005; 352:865-74.

16. Davies CW, Kearney SE, Gleeson FV, Davies RJ. Predictors of outcome and long-term survival in patients with pleural infection. Am J Respir Crit Care Med. 1999; 160:1682-7. https://doi.org/10.1164/ajrccm.160.5.9903002.

17. Sensenig DM, Rossi NP, Ehrenhaft JL. Results of the surgical treatment of bronchogenic carcinoma. Surg Gynecol Obstet. 1963; 116:279-84.

18. Leroux BT. Empyema Thoracis. Br J Surg. 1965; 52:89-99.

19. Takita H. Effect of postoperative empyema on survival of patients with bronchogenic carcinoma. J Thorac Cardiovasc Surg. 1970; 59:642-4.

20. Sekiguchi K, Oki S, Sugimoto H. Influence of empyema after resection for bronchogenic carcinoma and survival (cooperative study in Japan). Tohoku J Exp Med. 1979; 128:63-9. https://doi.org/10.1620/tjem.128.63.

21. Graham EA, Singer JJ. Successful removal of an entire lung for carcinoma of the bronchus. CA Cancer J Clin. 1974; 24:238-42. https://doi.org/10.3322/canjclin.24.4.238.

22. Sawabata N, Miyaoka E, Asamura H, Nakanishi Y, Eguchi K, Mori M, Nomori H, Fujii Y, Okumura M, Yokoi K, and Japanese Joint Committee for Lung Cancer Registration. Japanese lung cancer registry study of 11,663 surgical cases in 2004: demographic and prognosis changes over decade. J Thorac Oncol. 2011; 6:1229-35. https://doi.org/10.1097/ JTO.0b013e318219aae2.

23. Goldstraw P, Chansky K, Crowley J, Rami-Porta R, Asamura H, Eberhardt WE, Nicholson AG, Groome P, Mitchell A, 
Bolejack V, Goldstraw P, Rami-Porta R, Asamura H, et al, and International Association for the Study of Lung Cancer Staging and Prognostic Factors Committee, Advisory Boards, and Participating Institutions, and International Association for the Study of Lung Cancer Staging and Prognostic Factors Committee Advisory Boards and Participating Institutions. The
IASLC Lung Cancer Staging Project: Proposals for Revision of the TNM Stage Groupings in the Forthcoming (Eighth) Edition of the TNM Classification for Lung Cancer. J Thorac Oncol. 2016; 11:39-51. 